\title{
GESTÃO ORGANIZACIONAL EM APOIO À TOMADA DE DECISÃO: UMA ANÁLISE ATRAVÉS DAS PERSPECTIVAS ESTRATÉGICAS NA AMBIÊNCIA COOPERATIVISTA
}

\author{
Josefa Edileide Santos Ramos* \\ Marcelo da Costa Borba** \\ Maria do Carmo Maracajá Alves*** \\ Jose Eduardo Melo Barros**** \\ Andrea de Fátima de Oliveira Rego***** \\ Helio Beretta Dal Monte ${ }^{* * * * * *}$
}

RESUMO: O presente artigo toma por pressuposto que as decisões tomadas por uma cooperativa agrícola são complexas e envolvem múltiplos objetivos. Sendo assim, este artigo teve como objetivo analisar o processo de gestão organizacional, como ferramenta de apoio à tomada de decisão, de uma cooperativa agrícola na microrregião do Brejo paraibano. Quanto aos procedimentos metodológicos, esta pesquisa apresenta abordagem qualitativa através do estudo de caso com coleta de dados primários, entrevistas semiestruturadas e análise documental. $\mathrm{Na}$ análise foram consideradas as quatro dimensões do Balanced Scorecard além da avaliação geral da ferramenta. Os resultados mostraram que o mapeamento das ações pode ajudar no compartilhamento do conhecimento com os colaboradores e almejar ganhos mútuos com vantagens na economia de escala e na comercialização do produto final. O êxito dessa organização passa por um processo longo de monitoramento das ações, visando planejamento e controle estratégico organizacional. O estudo propôs um modelo de mapa estratégico, assim como faz uma proposta de projeção para os próximos quatro anos. A pesquisa fornece ainda um conjunto de indicadores estratégicos que podem ser de grande importância na tomada de decisão e de construção de um instrumento capaz de contribuir estrategicamente com o desempenho da cooperativa.

PALAVRAS-CHAVE: Cooperativismo Agrícola; Gestão Organizacional; Mapeamento Estratégico.

\footnotetext{
"Doutoranda em Agronegócios pela Universidade Federal do Rio Grande do Sul (UFRGS), Brasil. E-mail: edileideramos@gmail.com

*** Doutorando em Agronegócios pela Universidade Federal do Rio Grande do Sul (UFRGS), Brasil

**** Doutoranda em Ensino das Ciências pela Universidade Federal Rural do Pernambuco (UFRPE), Brasil.

**** Doutorando em Administração pela Universidade Federal da Paraíba (UFPB), Brasil.

****** Mestra em Administração pela Universidade Federal da Paraíba (UFPB), Brasil.

****** Doutor em Zootecnia pela Universidade Federal da Paraíba (UFPB), Brasil.
} 


\title{
ORGANIZATIONAL ADMINISTRATION BASED ON DECISION TAKING: ANALYSIS THROUGH STRATEGIC PERSPECTIVES WITHIN COOPERATIVES
}

\begin{abstract}
Current paper presupposes that decisions taken by an agricultural coop are complex and involve multiple aims. The paper analyzes the organizational administration process as a tool for decision taking of an agricultural coop in the Brejo microregion in the state of Paraíba, Brazil. Research is foregrounded on a qualitative approach through a case study, with the collection of primary data, semi-structured interviews and document analysis. Analysis involved the four dimensions of the Balanced Scorecard, coupled to a general evaluation of the tool. Results showed that the mapping of activities might help in the sharing of knowledge with collaborators and aims at gaining mutual advantages in scale economy and in the commercialization of the final product. The organization's success is a long process in the monitoring of activities, with planning and strategic control. The study proposes a model of strategic mapping and a projection for the next four years. Research also provides a set of strategic indexes of great importance in decision taking and the construction of a tool which is capable of contributing strategically with the coop's performance.
\end{abstract}

KEY WORDS: Agricultural coop; Organizational management; Strategic mapping.

\section{INTRODUÇÃO}

Nos últimos anos, o cooperativismo vem alcançando um papel de destaque no ambiente nacional, apresentando-se como uma alternativa inovadora de geração de trabalho e renda. Esta forma de gestão é capaz de unir desenvolvimento econômico e bem-estar social (KNICKEL et al., 2018). A força do cooperativismo se estende entre os pequenos e médios produtores e, nesse aspecto, a agricultura familiar representa a imensa maioria, mas também abrange as grandes unidades rurais do Brasil.

A motivação para a criação de cooperativas rurais vem da necessidade de aglutinação de forças dos produtores enquanto classe, e ainda, de enfrentamento de mercado buscando maiores oportunidades. A partir dessa necessidade surgem as cooperativas agrícolas para auxiliar no processo técnico de produção, no beneficiamento do produto, além da principal condição que é a comercialização (THOMAS; LOGAN, 2017). 
A escala de produção torna-se fator determinante para o escoamento da produção. Este é um dos principais problemas enfrentados pelos pequenos empreendimentos rurais sem escala, já que a comercialização é em função do volume disponível (ZIMMERMANN et al., 2018). Para essas empresas as principais estratégias de mercado são as ações coletivas como parcerias, associativismo, cooperativismo e a agregação de valor através da industrialização da produção (QIAO et al., 2018).

Essas cooperativas desempenham importante papel no desenvolvimento econômico e social de seus associados. Segundo Souza e Braga (2007, p. 01) os retornos econômicos originam-se da inserção dos pequenos e médios produtores em mercados concentrados e da agregação de valor à sua produção. Além da importância econômica, é relevante destacar a importância social atribuída a essas organizações, que são, em muitos casos, a única forma de organizar e comercializar a produção dos agricultores (SOUZA; BRAGA, 2007).

$\mathrm{O}$ cooperativismo possibilita acesso às estruturas comuns de apoio gerencial e mercadológico, permitindo, entre inúmeras vantagens, compartilhar os conhecimentos de gestão e de almejar ganhos mútuos com vantagens na economia de escala e na comercialização do produto final, em se tratando da pequena produção. A forma de gestão cooperativista tem seguido a via da agroindustrialização, como importante estratégia para a pequena produção agrária e a sua comercialização, de modo a agregar valor, gerar renda e oportunidades de trabalho no meio rural. Porém, os pequenos empreendimentos rurais têm enfrentado grandes dificuldades devido às exigências de mercado. Toda empresa necessita de métodos eficientes que possam controlar a gestão e garantir a sobrevivência desses estabelecimentos. Essa conotação foi observada em empreendimentos produtivos da fruticultura e da apicultura, que buscam desenvolvimento sustentável sob a gestão cooperativista como preceitos da autogestão democrática (ILIOPOULOS; VALENTINOV, 2018).

Este trabalho teve como objetivo analisar o processo de gestão organizacional, como ferramenta de apoio à tomada de decisão, de uma cooperativa agrícola na microrregião do Brejo paraibano. Especificamente pretendeu-se a) descrever as rotinas administrativas da cooperativa; b) identificar como se dá o processo de gestão de apoio à tomada de decisão gerencial; e c) propor um modelo de mapa estratégico para a organização baseado no Balanced Scorecard (BSC). 


\subsection{REFERENCIAL TEÓRICO}

Com o intuito de aprofundar o conhecimento sobre o tema estudado desenvolveu-se a pesquisa bibliográfica, abordando os temas: gestão cooperativista e gestão estratégica em cooperativas. Esses temas abordaram o significado do cooperativismo e a importância das cooperativas agropecuárias para os pequenos produtores rurais, além de abordar os modelos de gestão estratégica para esse modelo de organização.

\subsubsection{Gestão Cooperativista}

Existem significativas experiências de cooperação em todas as culturas e em todas as épocas. A natureza atua como um sistema, cada unidade precisa de outra para constituir um todo, onde as partes são integralizadas. Os seres humanos também fazem parte dessa natureza e necessitam uns dos outros para formação desse todo integrado e para a sua sobrevivência. Com isso, surge cada vez mais a necessidade da sociedade se organizar para fortalecer-se. Os termos cooperação e cooperativismo são diferentes, uma vez que a cooperação é algo inerente à socialização humana no decorrer do seu processo de desenvolvimento histórico. Já o cooperativismo é um movimento que surgiu com os ideais socialistas e tinha como meta principal possibilitar à classe operária uma sobrevivência mais digna em meio às desigualdades sociais proporcionadas pelo sistema capitalista (RÊGO; MOREIRA, 2013).

No cooperativismo, um grupo de pessoas se junta com os mesmos interesses, objetivando trabalhar com a comunidade dando sustentabilidade para as famílias. Desta forma a união de pessoas busca colocar seus produtos ou serviços no mercado em busca de melhores preços e vantagens que talvez não conseguiriam trabalhando individualmente. É importante acreditar na potencialidade do grupo como força transformadora (POLONIO, 2004).

As cooperativas possuem características diferentes das demais organizações, ainda que possuam alguns aspectos similares, uma vez que procura garantir sua eficiência econômica, eficácia social e preserva seus princípios doutrinários fundamentais. Manter o equilíbrio entre as dimensões sociais e econômicas é o princi- 
pal desafio do cooperativismo, e a perda de espaço para seus concorrentes vem da deficiência desses interesses na cooperativa (CHEN; LEE; CHEN, 2017; GIMENES; GIMENES, 2007).

Uma cooperativa pode ser definida como a posse e controle de um negócio em que busca o benefício de várias pessoas (HAKELIUS; HANSSON, 2016). Essa definição um tanto simples é amplamente aceita pela comunidade internacional de economistas agrícolas e pela Comissão Europeia (BENOS et al., 2016; BIJMAN et al., 2012). A estrutura de uma cooperativa é definida em três princípios: usuário-proprietário, usuário-fiscalizador, usuário-beneficiário (BIJMAN; HENDRIKSE; VAN OIJEN, 2013). O modelo organizacional tradicionalmente utilizado em cooperativas no meio rural também segue a lógica das demais cooperativas caracterizadas como posse exclusiva dos membros, controle democrático e uniforme (CHADDAD; ILIOPOULOS, 2013).

Neste sentido, Machado (2006) e Llull et al. (2017) comentam que as cooperativas devem se adaptar às necessidades do mercado para se manter em condições de competir. Acompanhar suas tendências e utilizar modelos de gestão eficientes para alcançar resultados satisfatórios, pois o desempenho econômico e de mercado é condição fundamental para o bom desempenho social das cooperativas. Para o sistema OCB (Organização das Cooperativas do Brasil), as organizações cooperativas, em busca de maior escala e força no mercado, se juntam a partir de processos de fusão e incorporação. Segundo dados do sistema o cooperativismo brasileiro está presente nos três setores da economia: primário, secundário e terciário, com maior participação de mercado nos ramos agropecuário, crédito e saúde (ANDRICH, 2013; TAVELLA; PAPADOPOULOS, 2017).

As cooperativas agropecuárias são organizações econômicas cuja propriedade é coletiva, constituídas por produtores rurais para fazer frente às falhas de mercado (COSTA; AZEVEDO; CHADDAD, 2012). O modelo organizacional tradicionalmente utilizado em cooperativas no meio rural também segue a lógica das demais cooperativas caracterizadas como posse exclusiva dos membros, controle democrático e uniforme (CHADDAD; ILIOPOULOS, 2013).

As atividades rurais podem ser praticadas de diversas maneiras desde o cultivo da pequena produção em face à sobrevivência, como grandes empresas explo- 
rando os setores agrícolas, pecuários e agroindustriais. A agricultura representa toda atividade de exploração da terra, seja tal atividade agrícola, zootécnica ou agroindustrial (BORILLI et al., 2005).

O cooperativismo agropecuário tem sua importância atribuída principalmente à sua função de inserção econômica de pequenos e médios produtores em mercados concentrados. Essas cooperativas desempenham importante papel econômico e social, principalmente pelo fato de representarem, em muitas regiões, uma das poucas possibilidades de agregação de valor à produção rural (BIJMAN et al., 2012; FERREIRA; BRAGA, 2004). A pequena propriedade agrícola pode ser incrementada pela implantação de cooperativas que passam a impulsionar o desenvolvimento econômico dos camponeses (RÊGO; MOREIRA, 2013).

Segundo Cechin et al. (2013) a função econômica das cooperativas é integrar verticalmente seus membros na cadeia de comercialização. Através de benefícios como a promoção da redução dos custos, por meio do poder de barganha na aquisição dos insumos; à melhoria da posição de barganha no mercado com ganhos de eficiência advindos da capacidade coordenadora das cooperativas (em especial quando se trata de produtos perecíveis); e à redução dos riscos em ações conjuntas, comuns a esse tipo de gestão.

De acordo com Dickel e Siluk (2015, p. 36), "as cooperativas têm sido importantes instituições para reforçar a posição econômica dos agricultores, uma vez que esta categoria precisa estar envolvida na constante negociação com os vendedores de insumos agrícolas ou compradores de produtos agrícolas". No entanto, a administração de uma cooperativa lida com os objetivos estabelecidos em assembleias. Isto cria um ambiente onde regras, valores e elementos de controle em geral podem apresentar-se de maneira peculiar. Desta forma, garantir um bom desempenho econômico é fundamental para enfrentar a competitividade do mercado. Assim, as cooperativas precisam consolidar modelos de gestão eficazes e efetivos.

\subsubsection{Gestão Estratégica nas Cooperativas}

Devido às constantes mudanças no contexto socioeconômico as cooperativas desenvolvem seus modelos de gestão, utilizando modernos instrumentos ad- 
ministrativos. Tais modelos variam de acordo com a realidade e as necessidades de cada organização. O modelo de gestão de Ribeiro et al. (2015) é conceituado como o processo interativo e consolidado de desenvolver as atividades de planejamento, organização, direção e avaliação, com foco no desenvolvimento e oportunidades de mercado para a cooperativa.

Para a funcionalidade do modelo de gestão, as cooperativas devem procurar o desenvolvimento da cultura organizacional, com o intuito de melhorar suas capacidades e consolidar uma reação para as constantes mudanças no mercado competitivo, as quais podem necessitar de novas abordagens de modelos de gestão.

Para o adequado desenvolvimento e aplicação do modelo de gestão na cooperativa, devem focar a amplitude global da cooperativa, sustentar o modelo de gestão com todos os sistemas e instrumentos, ter a metodologia correta, expandir barreiras, buscando a constante qualidade total. Porém para ser posta em prática o modelo de gestão, exige certa flexibilidade da cooperativa, para poder ser aplicada em diferentes situações que a cooperativa poderá encontrar no seu cotidiano (MACIEL et al., 2015, p. 3).

Com relação às cooperativas rurais, esses empreendimentos podem apresentar pouca capacidade de adaptação às mudanças do ambiente econômico em decorrência da alta taxa de informalidade presentes nesse meio e da dificuldade em assimilar informações técnicas gerenciais e mercadológicas voltadas para a produção. As pequenas cooperativas rurais sofrem a carência de informações no processo de gestão, o que repercute nas estratégias organizacionais aumentando ainda mais o desafio de seus gestores.

A fim de alcançar resultados satisfatórios as organizações definem seus objetivos. No entanto, precisam gerenciar suas atividades e recursos, a fim de orientá-los, surgindo a necessidade de ferramentas e metodologias que permitam às organizações configurar e otimizar seus sistemas de gestão. A gestão por processo traz uma nova abordagem de gestão, para superar a organização hierárquica tradicional, em que cada membro tem uma tarefa relacionada com o seu departamento funcional, para introduzir uma nova organização focada no cliente final através do conhecimento, controle e melhoria dos processos internos desenvolvidos (BRETOS; MARCUELLO, 2017; GINER FILLOL; RIPOLL FELIU, 2011)with the use of the Balanced Scorecard, the Port Authorities (AAPP. 
A gestão por processos de negócio (Business Process Management - BPM), que pode ser compreendida como uma abordagem que busca o alcance dos objetivos organizacionais através da melhoria, gestão e controle de processos essenciais para o alcance dos resultados desejados (IRITANI et al., 2015). As vantagens de se adotar esta abordagem incluem rapidez nas melhorias e mudanças de mercado, aumento da satisfação do consumidor, melhor qualidade de produtos, redução de custos e maior compreensão sobre as atividades da organização (KOHLBACHER, 2010).

Outra metodologia interessante é o Balanced Scorecard (BSC), que se constitui como um eficiente sistema de gestão estratégica, pois apresenta, em um único relatório, todos os indicadores importantes para o desempenho da organização. A respeito do BSC, Lunkes e Schnorrenberger (2009) explicam que essa ferramenta consiste em um conjunto de medidas de desempenho que são derivadas da estratégia da organização, servindo de base para um sistema de medição e gestão estratégica.

De acordo com Kaplan e Norton (desenvolvedores) o BSC se deu mediante a utilização de indicadores em quatro perspectivas: financeira, clientes, processos internos e aprendizagem e crescimento (RIBEIRO et al., 2015). O BSC trabalha medidas vetoriais, sendo de curto prazo como as financeiras, unidas às de longo prazo, como os clientes, processos internos e aprendizado e crescimento (PAGLIARIN et al., 2015).

A partir do que foi exposto, sugere-se uma proposta de modelo de mapa estratégico com base na metodologia do BSC em uma pequena cooperativa agrícola, como uma ferramenta de otimização do processo de gestão da organização. O mapa estratégico apresenta as estratégias da organização baseadas nas principais perspectivas do BSC, fundamentadas em uma relação de causa e efeito (POLO; HERNÁNDEZ; VÁZQUEZ, 2017; TAVARES, 2010). Esse é definido por meio de processos, ativos intangíveis, metas e iniciativas. 


\section{PROCEDIMENTOS METODOLÓGICOS}

Esta pesquisa tem uma abordagem qualitativa, trabalhada com técnicas de observação, em uma estrutura de estudo de caso, que consiste no estudo profundo e exaustivo de um ou poucos objetos, de maneira que permita seu amplo e detalhado conhecimento (GIL, 2008). Para Yin (2015, p. 32) "o estudo de caso é um estudo empírico que investiga um fenômeno atual dentro de seu contexto de realidade, quando as fronteiras entre o fenômeno e o contexto não são claramente definidas e no qual são utilizadas várias fontes de evidência". O estudo considera o método indutivo, onde o argumento passa do particular para uma questão mais ampla, em geral, uma vez que as generalizações derivam de observações de casos da realidade concreta (LAKATOS; MARCONI, 2017).

A pesquisa teve como objeto de estudo a Cooperativa Regional dos Produtores Rurais LTDA. (COAPRODES), com sede situada no município de Bananeiras, Microrregião do Brejo Paraibano. Foram realizadas de forma semestral entrevistas diretas e semiestruturadas, aplicadas aos dirigentes e funcionários em exercício, no período de quatro anos (2013-2017), totalizando nove semestres. Nesse período também foram realizadas visitas à cooperativa, com o intuito de visualizar as práticas administrativas e os processos diários. Fez-se levantamento de informações sobre o processo produtivo, caracterização e delineamento da abrangência de mercado, acrescentando-se ainda informação referente à comercialização e distribuição ao mercado consumidor.

Com a finalidade de atender aos objetivos propostos, foram necessárias as seguintes etapas: 1) pesquisa bibliográfica ou de fontes secundárias por meio de publicações de livros, revistas e periódicos; 2) pesquisa documental que se vale de materiais que ainda não receberam tratamento analítico, ou que ainda podem ser reelaborados de acordo com os objetos da pesquisa, como também existem aqueles que já foram processados, mas podem receber outras interpretações (GIL, 2008); 3) pesquisa de campo do tipo exploratório-descritiva que tem por objetivo descrever completamente determinados fenômenos e, segundo Lakatos e Marconi (2017), é apropriado para estudos de casos, de análises empíricas e teóricas.

No tocante à pesquisa de campo foi utilizada a coleta de dados in loco de 
documentos e de informações por meio de entrevistas semiestruturadas e por pesquisa participante observacional com rotina de visita semanal nos primeiros dois anos, em busca de dados que esclarecessem o processo degerencial praticado. As entrevistas foram aplicadas aos gestores (diretor administrativo e diretora executiva) e alguns funcionários (chefe de produção, secretária administrativa e contadora) da cooperativa, objetivando com essas entrevistas mapear os atuais processos e traçar as metas de cada perspectiva. Para a análise dos dados foram consideradas as quatro dimensões do Balanced Scorecard (Financeira, Clientes, Processos, aprendizado e crescimento), além de uma quinta variável, que é a avaliação geral em relação à ferramenta. Logo a pesquisa visa privilegiar a discussão em torno dos resultados das entrevistas, questionários, observação e documentos levantados, assim como a interpretação dos resultados obtidos.

\section{RESULTADOS E DISCUSSÕES}

Este item concentra a apresentação dos resultados e discussões obtidos junto à cooperativa do estudo de caso e a operacionalização dos objetivos da pesquisa. Assim, realiza-se a execução das análises propostas: a) descrição institucional que descreve as rotinas administrativas da cooperativa; b) diagnóstico organizacional que identifica como se dá o processo de gestão e decisão gerencial; e c) o mapa estratégico baseado no BSC.

\subsection{DESCRIÇÃO INSTITUCIONAL}

A COAPRODES constitui de forma itinerante um exemplo de cooperativismo. Atua como uma cooperativa agrícola que desenvolve atividades nos diversos setores: social, econômico e ambiental, desempenha suas atividades no beneficiamento do mel e polpa de frutas, tem suas atividades focalizadas na produção, armazenamento e comercialização. Beneficia o total de 221 cooperados, envolve 10 associações em 21 municípios da Paraíba que sobrevivem da agricultura familiar.

A COAPRODES surgiu a partir do desmembramento ou desenvolvimento da 
APRODES (Associação de Promoção ao Desenvolvimento Sustentável), que foi criada no ano de 2004, devido à necessidade de geração de renda e aproveitamento do potencial agrícola regional. A cooperativa tem como objetivo a comercialização de seus produtos, já que as associações não permitem a venda de produtos. Produzidos na sua sede, no município de Bananeiras, seus produtos abrangem mais de trinta municípios, localizados no Agreste, Borborema e Mata paraibana.

No ano de 2011 foi implementada na COAPRODES a unidade de beneficiamento de frutas. Com a implementação aumentou-se a escala de produção gerando estímulos aos cooperados com a agregação de valor à produção através do aperfeiçoamento do processo produtivo trazendo benefícios às famílias cooperadas. Para se entender o funcionamento estrutural da COAPRODES, Silva e Nascimento (2015) apresentaram o organograma da cooperativa (Figura 1). As responsabilidades foram alocadas de acordo com as atividades e as necessidades da organização.

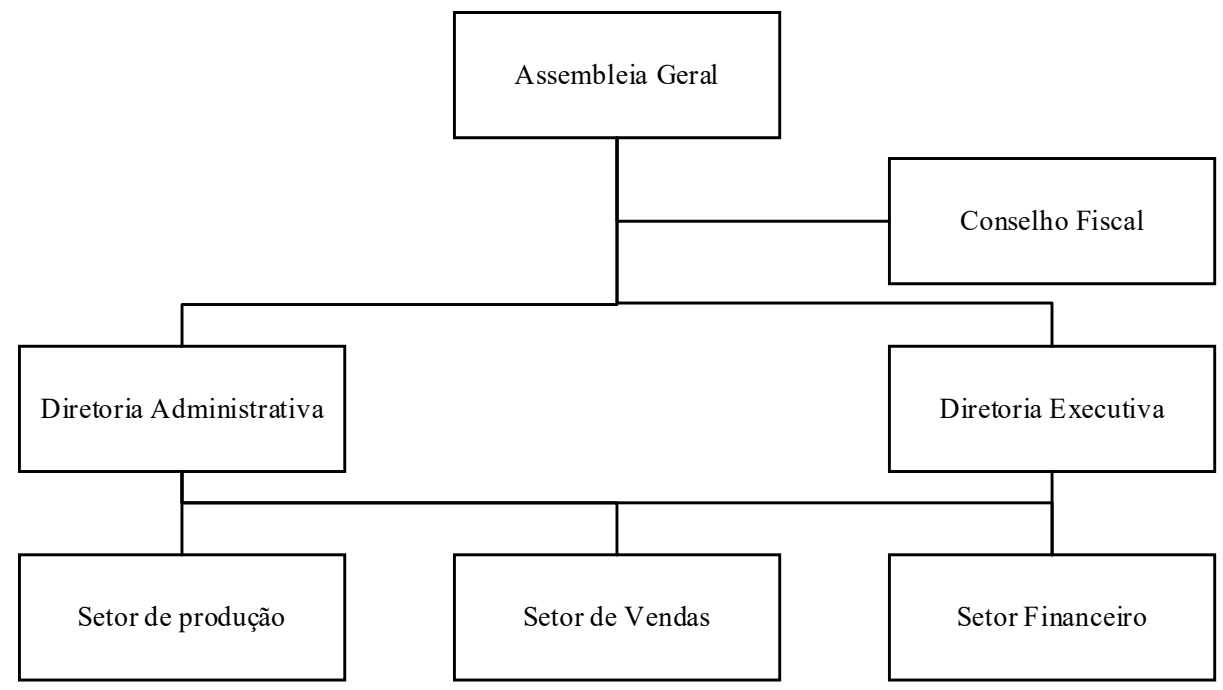

Figura 1. Organograma da COAPRODES Fonte: Silva e Nascimento (2015, p. 14).

A Assembleia Geral é responsável pelas decisões estratégicas da cooperativa. O conselho fiscal é responsável por fiscalizar as ações feitas pelas diretorias executiva e administrativa. $\mathrm{O}$ conselho se reúne apenas uma vez por ano para repasse de informações e não atua de maneira sólida nas atividades da cooperativa. As diretorias 
executiva e administrativa exercem as atividades de planejamento, execução, direção e controle das ações de curto prazo, além de assumir a responsabilidade das ações burocráticas e comercialização dos produtos. O setor produtivo é responsável pela recepção e beneficiamento das matérias-primas (mel e frutas). O setor de vendas realiza a comercialização e distribuição dos produtos acabados. O setor financeiro responsabiliza-se pela contabilidade e controle financeiro.

O setor de produção é responsável pelo beneficiamento da matéria-prima em produto acabado, seja ele mel ou frutas. As fontes de matéria-prima vêm dos próprios produtores rurais associados à cooperativa. As frutas são diversificadas e oriundas de regióes e períodos diferentes e o mel de apicultores também espalhados pelas dez associações que a compõem.

A cooperativa comercializa sua produção para a Companhia Nacional de Abastecimento (CONAB), o Programa Nacional de Alimentação Escolar (PNAE) e o comércio local. Cerca de 70\% da produção são distribuídos para a CONAB, 20\% para a o PNAE e apenas 10\% para o mercado privado o que torna a cooperativa quase em sua totalidade dependente das políticas governamentais. Identifica-se, então, uma necessidade de independência por parte da organização.

A distribuição dos produtos é realizada pela cooperativa nos pontos de entrega determinados pelo Ministério da Educação, sendo distribuídos no Estado da Paraíba para os municípios de Bananeiras, Arara, Solânea, Lagoa de Dentro, Cuité, Campina Grande, João Pessoa, Belém, Caiçara, Duas Estradas, Cuité, Picuí, Riachão, Itapororoca, Pirpirituba, Guarabira, Sapé. A comercialização limita-se a grandes distâncias devido à ausência de transporte adequado às exigências do Ministério da Agricultura. Quanto ao mercado privado, a cooperativa comercializa seus produtos no mercado por meio do contato interpessoal com o cliente, além de possuir um ponto de venda na sua unidade de beneficiamento.

Sua principal estratégia de venda é abatimento na venda do produto em grande escala, em que são mantidas duas tabelas de preço: uma contém o preço de mercado (utilizada para vendas em pequena quantidade); outra contém o valor de mercado com desconto (utilizada para vendas em grande quantidade). Quanto à formação do preço do produto vendido, a organização tem apresentado uma alternância nos preços. 
Constatou-se ainda que a formação de preço do produto não se baseia no custo de produção já que este não é calculado, mas vem sendo estimado no preço de mercado conforme a sazonalidade da matéria-prima. Sabe-se ainda que a maior parte da receita vem da venda de polpa de fruta, porque tem maior aceitação pelos clientes por apresentar uma maior quantidade de sabores, embalagens e preços.

\subsection{DIAGNÓSTICO ORGANIZACIONAL}

As organizações, de maneira geral, vivenciam algumas dificuldades no decorrer de sua administração, no entanto as cooperativas têm uma complexidade maior nesse aspecto por não possuírem, normalmente, uma gestão profissional. Isso se deve, em parte, pelo fato de sua normatização exigir serem autogeridas, independendo de toda boa vontade e dedicação que o gestor possa ter para atingir o objetivo organizacional, que é ser a intermediadora entre o mercado e seus cooperados (BIJMAN et al., 2012; LLULL et al., 2017).

Identificou-se, pelos resultados, uma gestão liderada por uma pessoa com largo conhecimento em cooperativas e associações, bem como dos associados e suas realidades. Diante dessa realidade, passou a ocorrer por parte dos gestores associados a necessidade de medir os custos de produção da polpa de fruta para o melhor embasamento das tomadas de decisão, que gradualmente estão sendo mais exigíveis considerando-se a ampliação de mercado.

Posteriormente, verificou-se certa desorganização, principalmente no tocante às informações da cooperativa encontrarem-se dispersas entre alguns de seus atores, como seu diretor-presidente e a contadora autônoma. Ademais, observou-se a falta de um planejamento estratégico, bem como de uma melhor e mais ativa relação com seu mercado consumidor privado de polpa de frutas e mel. Percebeu-se, ainda, a ausência de controle sobre que tipo de público-alvo é mais lucrativo, vez que possuem demanda superior à oferta.

Um entrave que ocorre na maioria dessas empresas coletivas é que suas decisões em assembleias são direcionadas para a simples prestação de serviços a seus associados, fazendo com que andem na contramão do mercado por não seguirem as tendências globais. O fato é que se a cooperativa não buscar a eficiência econômica 
ela não garantirá, em longo prazo, a melhora no nível de rendimentos do produtor e seu desenvolvimento regional (BENOS et al., 2016; POLO; HERNÁNDEZ; VÁZQUEZ, 2017).

O planejamento estratégico é peça essencial para o direcionamento das atividades gerenciais no sentido do alcance dos objetivos da organização em acordo com seu mercado para longo prazo. Nele são definidos os objetivos da empresa e como se fará para alcançá-los, além de proceder diversas análises internas e externas, como, por exemplo, de como ela está hoje e o que se deseja ser no futuro (HU; WILDBURGER; STROHHECKER, 2017).

Face ao exposto, uma das propostas para se alcançar a melhoria da gestão da COAPRODES é profissionalizar sua administração elaborando um planejamento estratégico para que a organização possa concorrer igualitariamente com as empresas privadas, que produzem em larga escala, e as demais cooperativas de frutas e mel do Estado. Sabe-se que para poder concorrer no mercado não é suficiente ofertar um bem semelhante aos demais, muito pelo contrário, é imprescindível para a sobrevivência da instituição que ela agregue valor ao seu produto através de estratégias competitivas diferenciadoras (DURÁN; CARRASCO; SEPÚLVEDA, 2018).

O cliente tem exigido cada vez mais das empresas, e o mercado, com suas crises econômicas, está produzindo alterações sociais, ambientais e econômicas que requererão decisões rápidas diferenciadas no sentido de atender às novas demandas desse ambiente mutável e tecnológico. Segundo Gutiérrez, Ávila e Trejo (2017), a atual postura empresarial é direcionar as organizações para papéis além da simples satisfação de uma necessidade premente, deve centrá-las para tornarem-se competitivas, agregarem valor aos seus produtos, através de valores que fomentem um mundo melhor, social, econômico e ambientalmente desejável.

Outro aspecto pesquisado foi o de gestão de pessoas entre os associados da cooperativa. A direção alegou que os associados não percebem a importância que possuem, individual e coletivamente, na instituição, e de seu trabalho para o desenvolvimento das comunidades envolvidas.

A frequência nas assembleias é pequena e muitos não consideram a participação nelas relevante por desconhecerem o poder que possuem. Assim, foi elaborada uma lista de ações para modificar esse quadro, utilizando de palestras informati- 
vas e motivacionais a respeito do que seja uma cooperativa e sua importância na vida de seus associados e da economia local, mostrando, inclusive, exemplos de sucesso na Paraíba e no Brasil.

Aspirou-se, também, preparar vídeos com as histórias de vida e superação de associados na produção de frutas e mel, de cartilhas didáticas e cursos. Mais uma ação será capacitar o conjunto gestor para iniciar e dar continuidade às formas administrativas mais viáveis aos objetivos da cooperativa e de seus integrantes, buscando conciliá-los aos ditames mercadológicos vigentes.

Da mesma forma que a equipe procura soluções para aperfeiçoar a gestão administrativa da COAPRODES, consegue ter clareza das dificuldades a serem vencidas, tais como a mudança na cultura organizacional, modificação na postura dos associados e empregados, o acesso às propriedades, a comunicação com os associados e baixo volume de capital para novos investimentos.

\subsection{MAPA ESTRATÉGICO DA COAPRODES}

Nessa perspectiva, este estudo propôs um modelo de mapa estratégico baseado na metodologia do BSC para a cooperativa. O levantamento de dados e informações envolveu uma série de componentes necessários como sistemas de informação que possam identificar e monitorar suas atividades, quer sejam operacionais ou de planejamento. Tais atividades estão relacionadas à execução das tarefas e operações cotidianas da organização, envolve o trabalho referente diretamente à produção. 
Quadro 1. Mapa Estratégico da COAPRODES

(Continua)

\begin{tabular}{|c|c|c|c|c|}
\hline & $\begin{array}{l}\text { Objetivos } \\
\text { Estratégicos }\end{array}$ & $\begin{array}{c}\text { Fator crítico } \\
\text { de sucesso }\end{array}$ & Metas & Ações \\
\hline \multirow{2}{*}{ 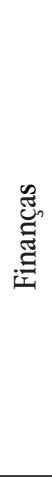 } & $\begin{array}{l}\text { Aumentar a } \\
\text { produção de } \\
\text { polpa de fruta } \\
\text { e mel. }\end{array}$ & $\begin{array}{l}\text { Desenvol- } \\
\text { vimento e } \\
\text { utilização } \\
\text { dos ativos. }\end{array}$ & $\begin{array}{l}\text { Ampliar a capacidade } \\
\text { produtiva da fábrica em } \\
\text { dez por cento anuais } \\
(2017-2020) .\end{array}$ & $\begin{array}{l}\text { Analisar a capacidade dos equi- } \\
\text { pamentos da fábrica; analisar } \\
\text { a capacidade de produção } \\
\text { dos funcionários; elaborar um } \\
\text { plano de produção para a coo- } \\
\text { perativa. }\end{array}$ \\
\hline & $\begin{array}{l}\text { Viabilizar eco- } \\
\text { nomicamente } \\
\text { as atividades } \\
\text { produtivas. }\end{array}$ & $\begin{array}{l}\text { Controle e } \\
\text { monitora- } \\
\text { mento eco- } \\
\text { nômico das } \\
\text { atividades. }\end{array}$ & $\begin{array}{l}\text { Colocar em funciona- } \\
\text { mento o plano de via- } \\
\text { bilização financeira das } \\
\text { atividades a partir de } \\
\text { agosto de } 2017 .\end{array}$ & $\begin{array}{l}\text { Ampliar a produção dos produ- } \\
\text { tos com maior rentabilidade; } \\
\text { viabilizar a produção de produ- } \\
\text { tos menos rentáveis. }\end{array}$ \\
\hline \multirow[b]{2}{*}{ 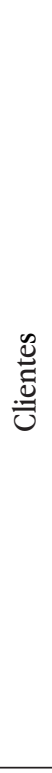 } & $\begin{array}{l}\text { Ampliar as par- } \\
\text { cerias com os } \\
\text { cooperados e } \\
\text { clientes. }\end{array}$ & $\begin{array}{l}\text { Dimensio- } \\
\text { namento } \\
\text { eficaz dos } \\
\text { stakebol- } \\
\text { ders. }\end{array}$ & $\begin{array}{l}\text { Atualizar o banco de } \\
\text { dados dos cooperados e } \\
\text { clientes a partir de agos- } \\
\text { to de } 2017 \text {, e ampliar } \\
\text { em quinze por cento o } \\
\text { número de clientes no } \\
\text { triênio (2018-2020). }\end{array}$ & $\begin{array}{l}\text { Revisar a o atual banco de da- } \\
\text { dos existente; incluir os novos } \\
\text { cooperados e clientes mais } \\
\text { recentes; expandir as parcerias } \\
\text { com novos clientes. }\end{array}$ \\
\hline & $\begin{array}{l}\text { Expandir o } \\
\text { canal de distri- } \\
\text { buição de toda } \\
\text { a produção. }\end{array}$ & $\begin{array}{l}\text { Mapeamen- } \\
\text { to da Logísti- } \\
\text { ca de coleta } \\
\text { da matéria } \\
\text { prima (mel } \\
\text { e frutas in } \\
\text { natura) e } \\
\text { entrega dos } \\
\text { produtos } \\
\text { industrializa- } \\
\text { dos. }\end{array}$ & $\begin{array}{l}\text { Desenvolver um plano } \\
\text { de roteirização semanal } \\
\text { para a coleta da maté- } \\
\text { ria-prima junto e para } \\
\text { a entrega dos produtos } \\
\text { industrializados aos } \\
\text { clientes a partir de agos- } \\
\text { to de } 2017 \text {. }\end{array}$ & $\begin{array}{l}\text { Roteirizar o processo de coleta } \\
\text { de matéria-prima e entrega de } \\
\text { produtos; analisar a rota mais } \\
\text { eficaz para escoamento da } \\
\text { produção; definir calendário de } \\
\text { coleta de matéria-prima e entre- } \\
\text { ga de produtos aos clientes. }\end{array}$ \\
\hline \multirow{2}{*}{ 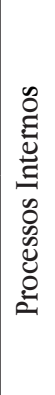 } & $\begin{array}{l}\text { Melhorar a } \\
\text { eficiência pro- } \\
\text { dutiva. }\end{array}$ & $\begin{array}{l}\text { Organização } \\
\text { dos proces- } \\
\text { sos produti- } \\
\text { vos. }\end{array}$ & $\begin{array}{l}\text { Diminuir as perdas na } \\
\text { produção em dez por } \\
\text { cento anuais no triênio } \\
(2018-2020) \text {. }\end{array}$ & $\begin{array}{l}\text { Identificar os processos com os } \\
\text { maiores gargalos; desenvolver } \\
\text { planos de melhorias nos pro- } \\
\text { cessos. }\end{array}$ \\
\hline & $\begin{array}{l}\text { Amplificar a } \\
\text { eficácia nos } \\
\text { processos ge- } \\
\text { renciais. }\end{array}$ & $\begin{array}{l}\text { Gerencia- } \\
\text { mento dos } \\
\text { recursos de } \\
\text { forma cor- } \\
\text { reta. }\end{array}$ & $\begin{array}{l}\text { Desenvolver um plano } \\
\text { de gestão eficiente dos } \\
\text { recursos humanos e tec- } \\
\text { nológicos nos próximos } \\
\text { três anos (2018-2020). }\end{array}$ & $\begin{array}{l}\text { Revisar os processos existentes; } \\
\text { descentralizar a tomada de } \\
\text { decisão; tornar os processos } \\
\text { gerenciais transparentes para os } \\
\text { colaboradores e cooperados. }\end{array}$ \\
\hline
\end{tabular}


(Conclusão)

\begin{tabular}{|c|c|c|c|c|}
\hline & $\begin{array}{c}\text { Objetivos } \\
\text { Estratégicos }\end{array}$ & $\begin{array}{c}\text { Fator crítico } \\
\text { de sucesso }\end{array}$ & Metas & Ações \\
\hline \multirow{2}{*}{ 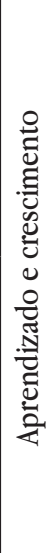 } & $\begin{array}{l}\text { Capacitar os } \\
\text { colaboradores e } \\
\text { cooperados. }\end{array}$ & $\begin{array}{l}\text { Capacitação } \\
\text { dos coope- } \\
\text { rados para } \\
\text { o uso de } \\
\text { tecnologias } \\
\text { limpas. }\end{array}$ & $\begin{array}{l}\text { Desenvolver um plano } \\
\text { de treinamento e assis- } \\
\text { tência técnica anual a } \\
\text { partir de setembro de } \\
2017 \text {. }\end{array}$ & $\begin{array}{l}\text { Firmar parcerias junto a órgãos } \\
\text { municipais para capacitação } \\
\text { dos cooperados; buscar parce- } \\
\text { rias com órgãos de ensino para } \\
\text { capacitar os colaboradores. }\end{array}$ \\
\hline & $\begin{array}{l}\text { Ampliar a } \\
\text { infraestrutura } \\
\text { tecnológica. }\end{array}$ & $\begin{array}{l}\text { Otimização } \\
\text { dos proces- } \\
\text { sos tecno- } \\
\text { lógicos de } \\
\text { produção e } \\
\text { comerciali- } \\
\text { zação. }\end{array}$ & $\begin{array}{l}\text { Implantar um sistema } \\
\text { de informação para o } \\
\text { controle de produção e } \\
\text { venda a partir de julho } \\
\text { de } 2017 \text {. }\end{array}$ & $\begin{array}{l}\text { Adquirir sistema de informação; } \\
\text { capacitar os colaboradores para } \\
\text { alimentar o sistema; monitorar } \\
\text { os dados inseridos. }\end{array}$ \\
\hline
\end{tabular}

Fonte: Elaborado pelos autores (2017).

A construção do mapa estratégico para a cooperativa objetiva contemplar as quatro perspectivas de conhecimento: finanças, clientes, processos internos, aprendizado e crescimento. Uma vez fixadas as quatro linhas a serem seguidas, passou-se para contextualização através dos objetivos estratégicos, fatores críticos de sucesso, metas e ações a serem desenvolvidas.

Na perspectiva financeira, o foco passa pela viabilização econômica das atividades produtivas e consequentemente aumentar a produção de polpa de fruta e mel, uma vez que a cooperativa sofre com a inviabilidade de produção e comercialização de alguns sabores de polpas de frutas. O entendimento é que haja uma diminuição gradativa no processamento em alguns sabores, ao mesmo tempo que se amplie a produção de sabores mais rentáveis. Com essa medida, há uma compreensão para aumento da capacidade produtiva da fábrica em dez por cento anuais, porcentagem traçada em decorrência da produtividade dos maquinários.

$\mathrm{Na}$ perspectiva do cliente os objetivos estratégicos têm a finalidade de ampliar as parcerias com os cooperados/clientes e expandir o canal de distribuição de toda a produção. Esses objetivos visam ampliar a área de distribuição e comercialização dos produtos - atualmente centralizada nas microrregiões do Brejo, Curimataú 
e Seridó - para toda a mesorregião do Agreste e Zona da Mata paraibana. Com esse planejamento, haverá a necessidade de firmar novas parcerias com os cooperados para o fornecimento de maior número de matéria-prima.

A perspectiva dos processos internos visa melhorar a eficiência produtiva e amplificar a eficácia nos processos gerenciais de forma a alinhar os processos produtivos e gerenciais. Esse alinhamento das metas gerenciais e produtivas mira a identificação e gerenciamento dos gargalos empresariais. Dentre as ações a serem desenvolvidas está a descentralização da tomada de decisão, tornando os processos gerenciais mais transparentes para os colaboradores e cooperados.

Por último, tem-se os objetivos da perspectiva do aprendizado e crescimento, os quais visam capacitação dos colaboradores/cooperados e ampliação da infraestrutura tecnológica da cooperativa. Esses aspectos miram a manutenção de ações de treinamentos direcionados à produção com qualidade e sustentabilidade (colaboradores/cooperados) e processos gerenciais e comerciais (colaboradores). $\mathrm{O}$ segundo objetivo dessa perspectiva se volta para a automação para a utilização total da capacidade produtiva dos maquinários, na tentativa de ampliar a produção com os atuais equipamentos.

Contudo, todos esses objetivos só terão uma maior eficácia se desenvolvidos em parcerias, pois os objetivos da perspectiva de aprendizado e crescimento funcionam como pilares necessários à melhoria dos processos internos, que por sua vez impulsiona a gestão da perspectiva dos clientes e consequentemente o êxito da perspectiva financeira. Na Figura 2 é possível visualizar a análise da influência dos objetivos estratégicos. 


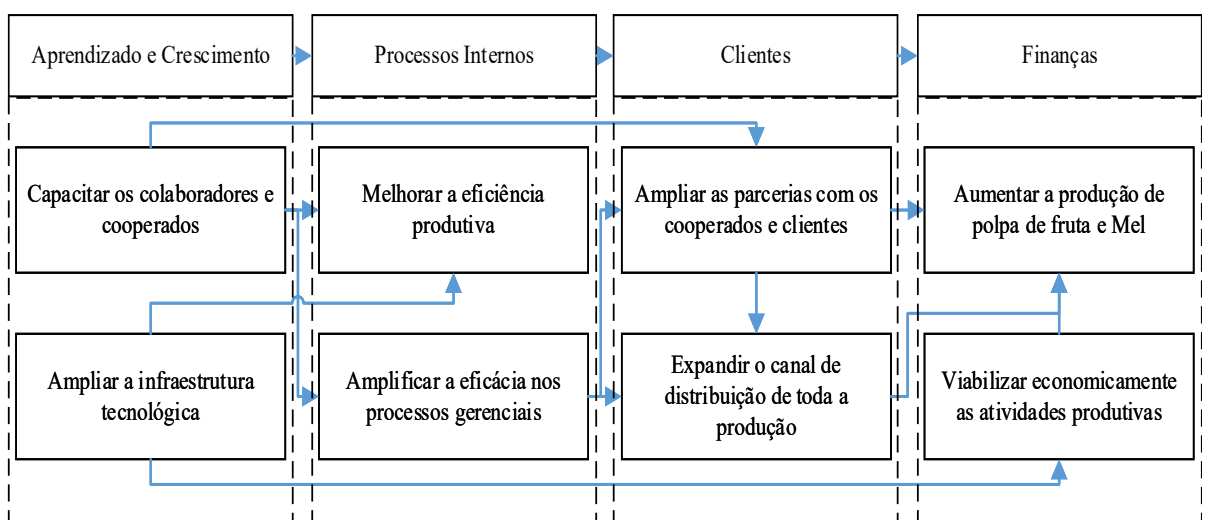

Figura 2. Análise da influência dos objetivos estratégicos Fonte: Elaborado pelo autor (2017).

Através da integração dos objetivos estratégicos é possível visualizar a importância de cada objetivo estratégico perante o pensamento organizacional traçado. Como pode ser visto a capacitação dos colaboradores gera impacto na melhoria da eficiência produtiva e eficácia operacional, que por sua vez ajuda na ampliação das parcerias com os cooperados e ampliação do canal de distribuição de toda a produção. Por outro lado, a ampliação da infraestrutura tecnológica irá gerar um controle maior da produção e consequentemente viabilização econômica das atividades produtivas. Portanto esses objetivos integrados irão gerar aumento na produção - objetivo principal do empreendimento.

\section{CONSIDERAÇÕES FINAIS}

A gestão cooperativista eficaz possibilita o acesso a informações gerenciais e mercadológicas, permitindo vislumbrar algumas vantagens competitivas. Ao desenvolver um mapeamento das ações é possível compartilhar conhecimento com os colaboradores e almejar ganhos mútuos com vantagens na economia de escala e na comercialização do produto final. Neste estudo a gestão cooperativista tem seguido a via da agroindustrialização como estratégia importante para o escoamento da produção agrária e sua comercialização, agregando valor, gerando renda e oportunidades de trabalho no meio rural.

Nesse sentido, entende-se que este estudo teve a função de auxiliar a coo- 
perativa na identificação, análise dos principais gargalos enfrentados pela gestão, possibilitando um controle dos indicadores de desempenho financeiros e não financeiros, à medida que propõe organizar os indicadores já definidos e utilizados pela cooperativa estudada, adequando-os às quatro perspectivas estabelecidas pelo BSC. Certamente que essa construção passou por um processo de amadurecimento gerencial, através de acompanhamento das atividades de forma semestral, gerando uma proposta permitiu à organização a readequação de seu planejamento estratégico a uma nova estrutura, bem mais clara e objetiva, apresentando as diretrizes gerais, onde os indicadores aparecem agrupados, e com uma leve dependência: finanças, clientes, processos internos, aprendizado e crescimento.

A partir das sucessivas entrevistas e visitas acompanhadas foi possível identificar fatores tanto positivos como negativos. Com esses fatores foi possível construir um mapa estratégico, objetivando facilitar a gestão de aspectos relacionados a finanças, clientes, processos internos, aprendizado e crescimento, possibilitando também a visualização de novos indicadores para desenvolvimento a longo prazo.

A utilização do mapa permitiu aos gestores da cooperativa ampliar o monitoramento sobre o desempenho da organização, uma vez que a partir dos objetivos estratégicos pôde-se desenvolver soluções para capacitação dos colaboradores, melhoria na eficiência e eficácia dos processos, ampliação do leque de parcerias e canais de distribuição, viabilização de atividades e aumento da produção.

A pesquisa analisa como uma pequena cooperativa agrícola na microrregião do Brejo paraibano organiza seu processo de gestão e como a concepção e desenvolvimento de uma ferramenta de gestão estratégica (BSC) pode auxiliar na gestão organizacional nesse tipo de empreendimento rural. Portanto, as análises desta pesquisa se concentram em todo o processo de implantação e revisão do BSC, assim como faz uma proposta de projeção para os próximos quatro anos. Por outro lado, representa apenas o início do estudo planejado, com resultados somente nos próximos três anos do acompanhamento e controle dos indicadores de desempenho financeiros e não financeiros da cooperativa.

Em linhas gerais, um dos pontos desta pesquisa está na construção do conhecimento relativo à gestão organizacional em cooperativas, em particular, contemplando as principais estratégias utilizadas por esses tipos de empreendimentos. A 
pesquisa fornece um conjunto de indicadores estratégicos que podem ser de grande importância na tomada de decisão, bem como na perspectiva de se construir um instrumento capaz de contribuir estrategicamente com o desempenho da cooperativa.

\section{AGRADECIMENTOS}

Agradecimentos à Cooperativa Regional dos Produtores Rurais LTDA. pela colaboração no desenvolvimento da pesquisa.

\section{REFERÊNCIAS}

ANDRICH, M. Focos nas Pessoas. Revista Brasileira de Administração, n. 94, 2013.

BENOS, T. et al. Cooperatives' organizational restructuring, strategic attributes, and performance: The case of agribusiness cooperatives in Greece. Agribusiness, v. 32, n. 1, p. 127-150, 2016.

BIJMAN, J. et al. Support for farmers' cooperatives. Sector Report Fruit and Vegetables, Wageningen, Wageningen UR, 2012.

BIJMAN, J.; HENDRIKSE, G.; VAN OIJEN, A. Accommodating Two Worlds in One Organization: Changing Board Models in Agricultural Cooperatives. Managerial and Decision Economics, v. 34, n. 3-5, p. 204-217, 2013.

BORILLI, S. P. et al. O uso da contabilidade rural como uma ferramenta gerencial: um estudo de caso dos produtores rurais no município de Toledo-PR. Revista Ciências Empresariais da UNIPAR, v. 6, n. 1, p. 77-95, 2005.

BRETOS, I.; MARCUELLO, C. Revisiting Globalization Challenges and Opportunities in the Development of Cooperatives. Annals of Public and Cooperative Economics, v. 88, n. 1, p. 47-73, 2017.

CECHIN, A. et al. Decomposing the member relationship in agricultural cooperatives: Implications for commitment. Agribusiness, v. 29, n. 1, p. 39-61, 2013. 
CHADDAD, F.; ILIOPOULOS, C. Control rights, governance, and the costs of ownership in agricultural cooperatives. Agribusiness, v. 29, n. 1, p. 3-22, 2013.

CHEN, H. H.; LEE, A. H. I.; CHEN, J. The relationship between innovation and performance in special nonprofit firms: Social and cooperative agrifood firms. Journal of Management \& Organization, v. 23, n. 4, p. 587-602, 2017.

COSTA, D. R. D. M.; AZEVEDO, P. F. DE; CHADDAD, F. R. Determinantes da separação entre propriedade e gestão nas cooperativas agropecuárias brasileiras. Revista de Administração, v. 47, n. 4, p. 281-595, 2012.

DICKEL, D. G.; MAIRESSE SILUK, J. C. Análise E Melhoria De Processos Operacionais Em Cooperativas: Uma Abordagem Estatística. Revista de Gestão e Organizações Cooperativas, v. 2, n. 4, p. 35-44, 2015.

DURÁN, C.; CARRASCO, R.; SEPÚLVEDA, J. Model of decision for the management of technology and risk in a port community. Decision Science Letters, v. 7, n. 3, p. 211-224, 2018.

FERREIRA, M. A. M.; BRAGA, M. J. Diversificação e competitividade nas cooperativas agropecuárias. Revista de Administração Contemporânea, v. 8, n. 4, p. 33-55, 2004.

GIL, A. C. Métodos e Técnicas de Pesquisa Social. 6 ed. São Paulo: Atlas, 2008.

GIMENES, R. M. T.; GIMENES, F. M. P. Agronegócio cooperativo: a transição e os desafios da competitividade. Revista Cadernos de Economia, v. 11, n. 20, p. 45$72,2007$.

GINER FILLOL, A.; RIPOLL FELIU, V. M. Análisis de la gestión por procesos y por competencias a través de la perspectiva de procesos y de aprendizaje y crecimiento: la experiencia de la autoridad portuaria de Valencia. Revista Universo Contábil, v. 7, n. 2, p. 114-129, 2011.

GUTIÉRREZ, J. S.; ÁVILA, G. V.; TREJO, J. M. Marketing and elementa influencing the competitiveness of commercial micro, small and medium-sized enterprises in 
Guadalajara, Mexico. Innovar, v. 27, n. 65, p. 93-106, 2017.

HAKELIUS, K.; HANSSON, H. Measuring Changes in Farmers' Attitudes to Agricultural Cooperatives: Evidence from Swedish Agriculture 1993-2013. Agribusiness, 2016.

HU, B.; WILDBURGER, U. L.; STROHHECKER, J. Strategy map concepts in a balanced scorecard cockpit improve performance. European Journal of Operational Research, v. 258, n. 2, p. 664-676, 2017.

ILIOPOULOS, C.; VALENTINOV, V. Member heterogeneity in agricultural cooperatives: A systems-theoretic perspective. Sustainability, v. 10, n. 4, p. 1271, 2018.

IRITANI, D. R. et al. Análise sobre os conceitos e práticas de Gestão por Processos: revisão sistemática e bibliometria. Gestão \& Produção, v. 22, n. 1, p. 164-180, 2015.

KNICKEL, K. et al. Between aspirations and reality: Making farming, food systems and rural areas more resilient, sustainable and equitable. Journal of Rural Studies, v. 59, p. 197-210, 2018.

KOHLBACHER, M. The effects of process orientation: a literature review. Business Process Management Journal, v. 16, n. 1, p. 135-152, 2010.

LAKATOS, E. M.; MARCONI, M. DE A. Fundamentos de Metodologia Científica. 8. ed. São Paulo: Atlas, 2017.

LLULL, Q. et al. Cooper: Task Colocation with Cooperative Games. Proceedings International Symposium on High-Performance Computer Architecture, p. 421-432, 2017.

LUNKES, R. J.; SCHNORRENBERGER, D. Controladoria na coordenação dos sistemas de gestão. São Paulo: Atlas, 2009.

MACHADO, S. M. C. F. Gestão de Cooperativa: um estudo de caso. [s.l.] Faculdade de Ciências Contábeis, 2006.

MACIEL, A. C. S. et al. Gestão financeira de uma cooperativa agroindustrial: prá- 
ticas de gerenciamento e análise financeira. Revista de Gestão e Organizações Cooperativas, v. 2, n. 3, p. 71-82, 2015.

PAGLIARIN, L. LONDERO et al. O planejamento estratégico em uma organização de insumos agrícolas a partir de uma adaptação do Balanced Scorecard. Revista de Gestão e Organizações Cooperativas, v. 2, n. 3, p. 97-112, 2015.

POLO, F. C.; HERNÁNDEZ, M. I. S.; VÁZQUEZ, D. G. Assessing the Influence of Social Responsibility on Reputation: An Empirical Case-Study in Agricultural Cooperatives in Spain. Journal of Agricultural and Environmental Ethics, v. 30, n. 1, p. 99-120, 2017.

POLONIO, W. A. Manual das sociedades cooperativas. 4. ed. São Paulo: Atlas, 2004.

QIAO, Y. et al. Certified Organic Agriculture as an Alternative Livelihood Strategy for Small-scale Farmers in China: A Case Study in Wanzai County, Jiangxi Province. Ecological Economics, v. 145, p. 301-307, 2018.

RÊGO, E. E. DO; MOREIRA, E. Cooperaticismo: uma breve discussão teórico-conceitual perpassando pelo socialismo utópico, marxista e anarquista. Revista OKARA: Geografia em debate, v. 7, n. 1, p. 63-80, 2013.

RIBEIRO, R. R. M. et al. Aplicação de um Modelo Gerencial Estratégico Baseado no Balanced Scorecard no Processo Produtivo do Álcool, Açúcar e Subprodutos em uma Cooperativa do Setor Sucroalcooleiro. In: CONGRESSO INTERNACIONAL DE ADMINISTRAÇÃO DA AMERICA LATINA, Anais [...]. Ponta Grossa: 2015.

SILVA, M. E.; NASCIMENTO, F. DOS S. Análise da Gestão de uma Cooperativa de Produtores Rurais no Município de Bananeiras-PB. In: $53^{\circ}$ CONGRESSO DA SOBER-SOCIEDADE BRASILEIRA DE ECONOMIA ADMINISTRAÇÃO E SOCIOLOGIA RURAL. Anais [...]. João Pessoa: Sober Nacional, 2015.

SOUZA, U. R. DE; BRAGA, M. J. Diversificação concêntrica na cooperativa agropecuária: um estudo de caso da COMIGO. Gestão e Produção, v. 14, n. 1, p. 169179, 2007.

TAVARES, M. C. Gestão estratégica. São Paulo: Atlas, 2010. 
TAVELLA, E.; PAPADOPOULOS, T. Applying OR to problem situations within community organisations: A case in a Danish non-profit, member-driven food cooperative. European Journal of Operational Research, v. 258, n. 2, p. 726-742, 2017.

THOMAS, H.; LOGAN, C. Mondragon: An economic analysis. London: Routledge, 2017.

YIN, R. K. Estudo de Caso: Planejamento e Métodos. Rio de Janeiro: Bookman Editora, 2015.

ZIMMERMANN, M. et al. Carrot and stick: A game-theoretic approach to motivate cooperative driving through social interaction. Transportation Research Part C: Emerging Technologies, v. 88, p. 159-175, 2018.

Recebido em: 29/07/2017

Aceito em: 29/08/2018 